\title{
Engraftment of engineered ES cell-derived cardiomyocytes but not BM cells restores contractile function to the infarcted myocardium
}

\author{
Eugen Kolossov, ${ }^{1}$ Toktam Bostani, ${ }^{2}$ Wilhelm Roell, ${ }^{3}$ Martin Breitbach, ${ }^{2}$ \\ Frank Pillekamp, ${ }^{4,6}$ Jens M. Nygren, ${ }^{7}$ Philipp Sasse, ${ }^{2}$ Olga Rubenchik, ${ }^{4}$ \\ Jochen W.U. Fries, ${ }^{5}$ Daniela Wenzel, ${ }^{2}$ Caroline Geisen, ${ }^{2}$ Ying Xia, ${ }^{4}$ \\ Zhongju Lu, ${ }^{4}$ Yaqi Duan, ${ }^{4}$ Ralf Kettenhofen, ${ }^{1}$ Stefan Jovinge, ${ }^{7}$ \\ Wilhelm Bloch, ${ }^{8}$ Heribert Bohlen, ${ }^{1}$ Armin Welz, ${ }^{3}$ Juergen Hescheler, ${ }^{4}$ \\ Sten Eirik Jacobsen, ${ }^{7}$ Bernd K. Fleischmann ${ }^{2}$ \\ ${ }^{1}$ Axiogenesis AG, 50931 Cologne, Germany \\ ${ }^{2}$ Institute of Physiology I and ${ }^{3}$ Department of Cardiac Surgery, University of Bonn, 53105 Bonn, Germany \\ ${ }^{4}$ Institute of Neurophysiology, ${ }^{5}$ Department Pathology, and ${ }^{6}$ Department of Pediatric Cardiology, University of Cologne, 50931 \\ Cologne, Germany \\ ${ }^{7}$ Hematopoietic Stem Cell Laboratory, Lund Strategic Research Center for Stem Cell Biology and Cell Therapy, Lund University, \\ 22100 Lund, Sweden \\ ${ }^{8}$ German Sports University, 50927 Cologne, Germany
}

CORRESPONDENCE

Bernd K. Fleischmann:

bernd.fleischmann@uni-bonn.de $\mathrm{OR}$

Eugen Kolossov:

eugen.kolossov@axiogenesis.com

Abbreviations used: $\alpha-\mathrm{MHC}$, $\alpha$-myosin heavy chain; ASMAC, $\alpha$-smooth muscle actin; EB, embryoid body; EGFP, enhanced GFP; ES cell, embryonic stem cell; LCA, left coronary artery; LVEF, left ventricular ejection fraction;

LVF, left ventricular function; MEA, microelectrode array; PECAM, platelet/endothelial cell adhesion molecule.

Cellular cardiomyoplasty is an attractive option for the treatment of severe heart failure. It is, however, still unclear and controversial which is the most promising cell source. Therefore, we investigated and examined the fate and functional impact of bone marrow (BM) cells and embryonic stem cell (ES cell)-derived cardiomyocytes after transplantation into the infarcted mouse heart. This proved particularly challenging for the ES cells, as their enrichment into cardiomyocytes and their long-term engraftment and tumorigenicity are still poorly understood. We generated transgenic ES cells expressing puromycin resistance and enhanced green fluorescent protein cassettes under control of a cardiac-specific promoter. Puromycin selection resulted in a highly purified $(>99 \%)$ cardiomyocyte population, and the yield of cardiomyocytes increased 6-10-fold because of induction of proliferation on purification. Long-term engraftment (4-5 months) was observed when co-transplanting selected ES cell-derived cardiomyocytes and fibroblasts into the injured heart of syngeneic mice, and no teratoma formation was found $(n=60)$. Although transplantation of ES cell-derived cardiomyocytes improved heart function, BM cells had no positive effects. Furthermore, no contribution of BM cells to cardiac, endothelial, or smooth muscle neogenesis was detected. Hence, our results demonstrate that ES-based cell therapy is a promising approach for the treatment of impaired myocardial function and provides better results than BM-derived cells.

Cell replacement is heralded as an attractive therapeutic option for the treatment of heart failure (for review see reference 1), a disorder characterized by a very poor 5 -yr survival rate. The only effective treatment is currently achieved by solid organ transplantation.

We and others have demonstrated that cellular replacement therapy using contractile cells

E. Kolossov, T. Bostani, W. Roell, and M. Breitbach contributed equally to this work.

The online version of this article contains supplemental material. is a valid alternative (1). At the moment there are contrasting views as to which cell type may be best suited for cellular cardiomyoplasty $(1,2)$. In the past few years, attention has focused on the "transdifferentiation" of BM cells into cardiomyocytes (3) as a source of cardiomyocyte replacement in the damaged heart. However, recent studies in mice question these findings $(4,5)$, and new evidence suggests that potentially paracrine effects (6) and/or neovascularization (7), not neogenesis of the myocardium, may have beneficial effects. Thus, it is 
still unclear whether and to which degree transplantation of BM cells results in improvement of defective heart function after infarction.

Because embryonic stem cells (ES cells) can differentiate into all different cell types (pluripotency), they represent an excellent starting population for the generation of cells in regenerative medicine (for review see references 1, 8). However, there are still substantial hurdles to overcome before ES cells can be exploited for therapeutic purposes. A principle problem in particular for muscle cells (9) is the difficulty in obtaining sufficient quantities of high quality cells. Although earlier studies addressed the purification $(10,11)$ and transplantation of ES cell-derived cardiomyocytes into a very small cohort of mice (10), the best preparation to ensure long-term engraftment, their fate after transplantation, and the impact of these cells on heart function in vivo is unknown. Alternative approaches using undifferentiated mouse ES cells in xenomodels appear inconclusive $(12,13)$, because cell differentiation is known to be critically dependent on signals provided from the host tissue. Most importantly, xenomodels bear little predictability with respect to tumorigenicity $(14,15)$, which is still a very substantial problem with ES cell-based transplantation strategies, because teratomas are rejected in xenografts (16).

Thus, the different cellular sources for improvement of cardiac function remain of considerable interest to explore (1), but few if any studies have directly examined the potential of different cell types in the same models. We have therefore determined in the present study fate and functional impact of BM cells, as well as noncardiomyocytes and ES cell-derived cardiomyocytes, after transplantation into infarcted mouse hearts.

\section{RESULTS \\ Fate and functional impact of BM cells in the infarcted mouse heart}

We have used cryoinjury (17) or left coronary artery (LCA) ligation (Fig. $1 \mathrm{~A}$ ) to induce large left ventricular infarctions. For hemodynamic studies the first injury model is preferable, as highly reproducible lesions are generated even in the mouse (17). Enhanced $\mathrm{GFP}^{+}\left(\mathrm{EGFP}^{+}\right) \mathrm{BM}$ cells $\left(3 \times 10^{6}\right)$ were injected into the center and the border zone of the infarction as previously described $(3,5)$, and hearts were analyzed 3-4 wk later. Catheterization revealed no improvement of left ventricular ejection fraction (LVEF) and other functional parameters (not depicted) compared with sham-injected mice (Fig. $1 \mathrm{O}$ and Table S1, available at http://www.jem.org/cgi/ content/full/jem.20061469/DC1), whereas morphological analysis of cryosections revealed considerable engraftment of $\mathrm{EGFP}^{+}$cells in the scar region (Fig. 1 D). To test whether a higher percentage of BM-derived stem cells is required to enhance left ventricular function (LVF), recipient mice were lethally irradiated, reconstituted with transgenic BM cells (5), and, after assessment of good engraftment $(>80 \%)$, heart infarction (cryoinfarction or LCA ligation) and cytokine mobilization were performed. The integration of $\mathrm{EGFP}^{+}$cells in and around the injury site was massive 3-4 wk after operation in both lesion models (Fig. 1, B and C) and clearly higher than after direct injection (Fig. 1 D). However, measurements of LVEF also yielded no improvement in these mice compared with the sham-injected controls after cryoinjury (Fig. $1 \mathrm{P}$ and Table S1) and after LCA ligation (49.6 $\pm 6.1 \%$ $[n=4]$ in the mobilized vs. $54.6 \pm 3.3 \%[n=3]$ in the nonmobilized control group; Table S1). Note that lesion sizes in LCA-infarcted animals can vary.

To determine in more detail the effects of directly injecting or mobilizing BM cells, hearts were harvested and analyzed by immunohistochemistry. In accordance with function, no obvious morphological differences were noted in cryoinjured and LCA-ligated versus control hearts. Cytokineinduced mobilization led also to infiltration of $\mathrm{EGFP}^{+}$cells in intact myocardium (Fig. 1 E). Two different shapes of EGFP ${ }^{+}$ cells, round and more elongated, were identified; the latter was more frequent in the border zone of the lesion and in the intact myocardium (Fig. 1, G and H). The EGFP ${ }^{+}$cells in the scar region (Fig. 1 F) and in the border zone (Fig. 1, G and $\mathrm{H}$ ) were positive for the panhematopoietic marker CD45 and negative for the muscle marker cardiac $\alpha$-actinin. Consistent with our earlier findings (5), a few morphologically intact $\mathrm{EGFP}^{+}$cardiomyocytes originating through cell fusion were found. Large (Fig. 1 I) and small (Fig. 1, J and K) vessels in and around the scar region were stained with the endothelial markers platelet/endothelial cell adhesion molecule (PECAM) or von Willebrand factor (unpublished data) and with $\alpha$-smooth muscle actin (ASMAC), and all theses vessels were found to be EGFP ${ }^{-}$. Some of the small vessels lacked the smooth muscle layer (Fig. 1 J), which is a typical finding for newly formed vessels in the lesion. Occasionally, $\mathrm{EGFP}^{+}$/ $\mathrm{PECAM}^{-} / \mathrm{ASMAC}^{-}$cells were detected in the lumen or even below the endothelial cell layer of small vessels (Fig. $1 \mathrm{~K}$ ), indicating transmigrating hematopoietic cells.

To further exclude potential initiation or ongoing cardiac transdifferentiation of $\mathrm{EGFP}^{+}$cells with a different technique than immunohistochemistry, we characterized the functional expression of ion channels using patch clamp; this technique provides a highly sensitive readout of the functional and developmental status of cells (18). Isolated cells were obtained from mobilized hearts after collagenase treatment, and both $\mathrm{EGFP}^{+}$and $\mathrm{EGFP}^{-}$cells were investigated. We found that all $\mathrm{EGFP}^{+}$cells had a small membrane capacitance $(7.1 \pm 0.1 \mathrm{pA} / \mathrm{pF} ; n=7)$ and functionally did not express voltage-dependent inward currents $(n=15$; Fig. $1 \mathrm{~N}$, right), a hallmark of cardiomyocytes starting from early embryonic development (Fig. $1 \mathrm{M}$, inset) (9, 18). In contrast, native cardiomyocytes harvested from the same hearts were $\mathrm{EGFP}^{-}$, had distinct cross-striation (Fig. $1 \mathrm{~N}$, inset), a large membrane capacitance (127.2 $\pm 22.4 \mathrm{pA} / \mathrm{pF} ; n=7)$, and expressed $\mathrm{I}_{\mathrm{Na}}$ and $\mathrm{I}_{\mathrm{Ca}}($ Fig. $1 \mathrm{M})$. Accordingly, action potentials could be evoked by depolarizing voltage ramps in $\mathrm{EGFP}^{-}(n=3$; Fig. $1 \mathrm{~L})$ but not $\mathrm{EGFP}^{+}$cells $(n=11$; Fig. $1 \mathrm{~N}$, left), where only outwardly rectifying $\mathrm{K}^{+}$currents were found ( $n=15$; Fig. $1 \mathrm{~N}$, right). 
A
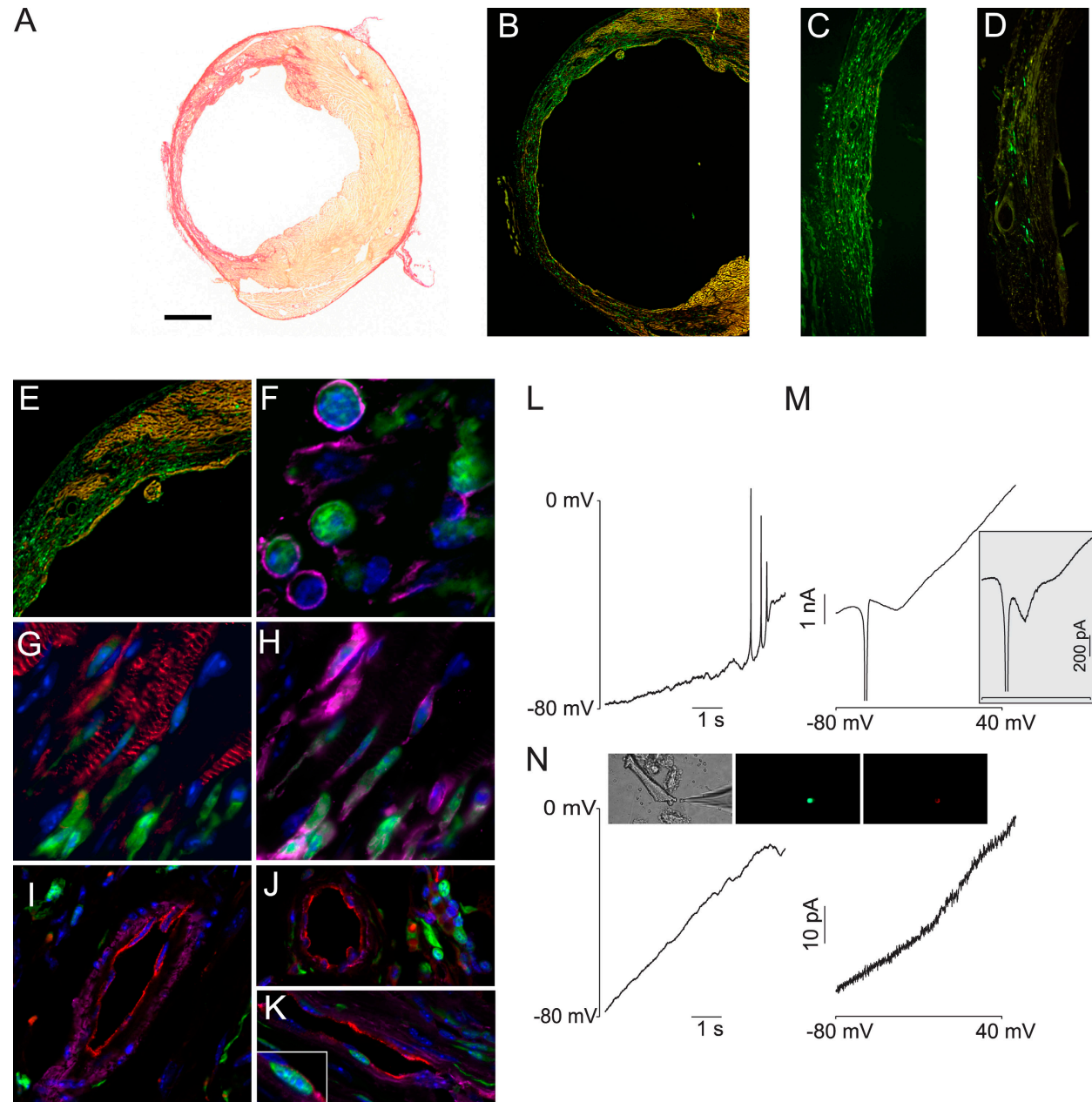

\section{O}

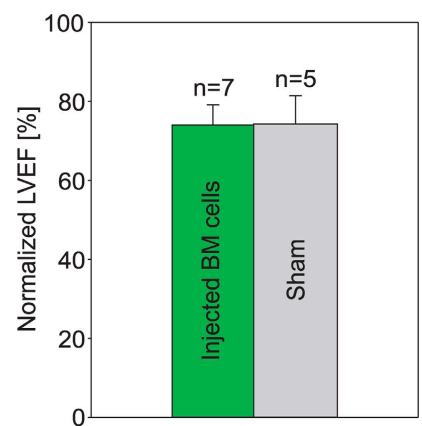

Figure 1. Engraftment and characterization of BM cells after direct injection or cytokine mobilization in the infarcted heart, including impact on heart function. (A) Sirius red staining shows extended scar (red) formation in an infarcted heart 4 wk after LCA ligation. (B-D) Engraftment of large numbers of EGFP+ cells after cytokine mobilization ( $B$ and $C$ ) and direct injection of BM cells (D) 4 wk after infarction. (E) Increased engraftment of EGFP+ cells in the border zone and the native myocardium after mobilization. $(\mathrm{F}-\mathrm{H}) \mathrm{EGFP}+$ cells were $\mathrm{CD}^{+} 5^{+}(\mathrm{Cy} 5$, magenta; $\mathrm{F}$ and $\mathrm{H})$ and $\alpha$-actinin ${ }^{-}$(Cy3, red; F and $\left.\mathrm{G}\right)$ within the scar (F) and in the border zone ( $\mathrm{G}$ and $\mathrm{H})$. (I-K) Large (I) and small $(\mathrm{J}$ and $\mathrm{K})$ vessels in the infarcted area were $\mathrm{PECAM}^{+}(\mathrm{Cy} 3$, red) and $\mathrm{ASMAC}^{+}(\mathrm{Cy} 5$, magenta) but EGFP-; some small vessels lacked the smooth muscle layer $(J)$. Note the EGFP+ transmigrating cell (K, inset).
L M
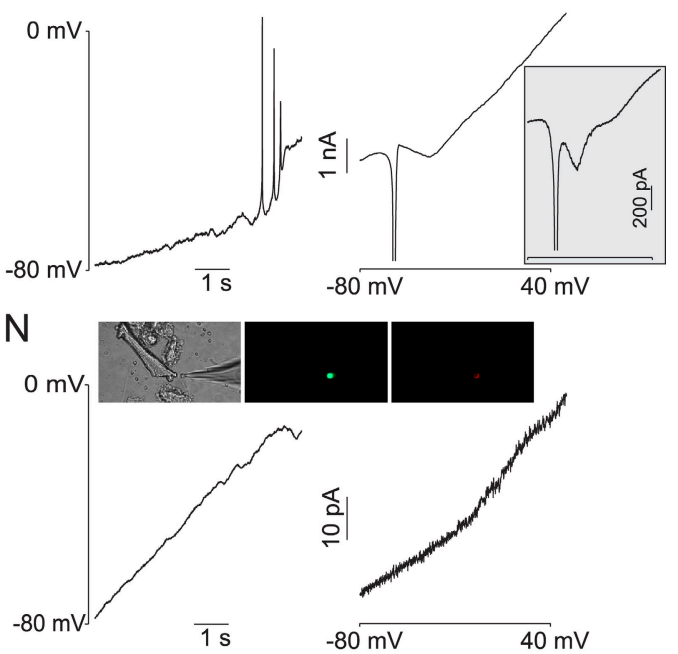

$\mathrm{P}$

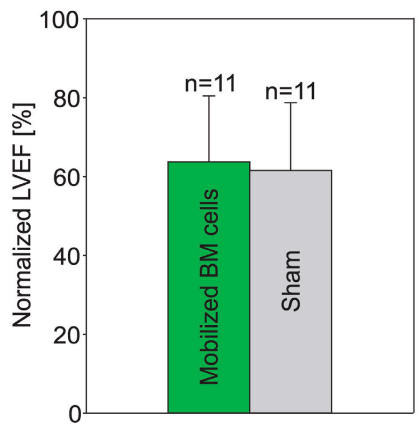

Nuclei were stained with Hoechst dye (blue). (L-N) Depolarizing current ramps (10 s) evoked action potentials in EGFP- cardiomyocytes (L) but not in $\mathrm{EGFP}^{+}$cells ( $\mathrm{N}$, left). ( $\mathrm{M}$, inset; and $\mathrm{N}$, right) Voltage ramps ( -80 to $+50 \mathrm{mV}, 250 \mathrm{~ms}$ ) evoked inward currents in adult (M) and embryonic (E9.5; $\mathrm{M}$, inset) cardiomyocytes but not in EGFP+ cells ( $\mathrm{N}$, right). Images show transmission and fluorescent images of a patched cell (EGFP, green; CD45, red). (0 and P). Statistics of LVEF $3-4$ wk after infarction using catheterization. The values are normalized to data obtained from WT C57BL/6 mice $(n=6)$. Original data are listed in Table S1. Note that mice that underwent cytokine mobilization $(P)$ show reduced LVEF, which was likely caused by irradiation ( $P=0.95[0]$ and $0.77[P]$, respectively). Bars: (A) $900 \mu \mathrm{m}$; (B) $550 \mu \mathrm{m}$; (C) $250 \mu \mathrm{m}$; (D) $300 \mu \mathrm{m}$; (E) $400 \mu \mathrm{m}$; (F) $15 \mu \mathrm{m} ;(\mathrm{G}$ and $\mathrm{H}) 20 \mu \mathrm{m} ;(\mathrm{I}-\mathrm{K}) 35 \mu \mathrm{m}$. 


\section{Transplantation of undifferentiated ES cells and nonpurified ES cell-derived cardiomyocytes}

Because we found no evidence for BM transplantation improving cardiac function or differentiation of BM cells into cardiomyocytes, endothelial cell, or smooth muscle cells, we next investigated ES cells as an alternative cellular source for cardiomyoplasty.

Because of contrasting earlier reports (12-14), we first determined the tumorigenicity of undifferentiated ES cells by injecting $10^{6}$ cells $(n=2)$ into the tail vein or $10^{5}$ cells $(n=14)$ directly into infarcted hearts. Large tumor masses were detected in all syngeneic $(n=13)$ and 2 out of 3 allogeneic animals within 4 wk (see Fig. 6 E). The onset of tumor growth occurred as early as $10 \mathrm{~d}$ after ES cell transplantation. Next, we excised beating $\mathrm{EGFP}^{+}$areas from transgenic $\alpha-$ myosin heavy chain ( $\alpha$-MHC)-EGFP embryoid bodies (EBs) (9) to enrich for cardiomyocytes and reduce the number of undifferentiated ES cells. After injection $\left(10^{5}\right.$ cells), tumor growth was still detected in the majority of mice (five out of six; Fig. 2, A-C; and see Fig. 6 E) but with delayed onset. Histological analysis of the tumors revealed glandular (endoderm), squamous epithelium (ectoderm), and cartilage (mesoderm) differentiation (Fig. 2, D and E), hence typical histological features of teratomas. These results indicated that highly purified ES cellderived tissue preparations are required to minimize the risk for tumor generation.

\section{Puromycin-based selection and induction of proliferation of ES cell-derived cardiomyocytes}

To purify and identify ES cell-derived cardiomyocytes, we generated a bicistronic vector in which the cardiac-specific promoter $\alpha-\mathrm{MHC}$ drives the expression of both the puromycin resistance gene and the EGFP cassette (Fig. 3 A, top). Two clones ( $\alpha$ PIG10 and $\alpha$ PIG44) were chosen for further study and differentiated in vitro using the hanging drop or mass culture protocol. The first clusters of EGFP ${ }^{+}$ cells were detected in the EBs on days 7-8 of development, and spontaneous beating began $\sim 12-24$ h later. $10 \mu \mathrm{g} / \mathrm{ml}$ puromycin was added to the culture dishes on days $9-10$ (Fig. 3 A, left), and EGFP fluorescence and contractile activity of the $\mathrm{EGFP}^{+}$clusters intensified during the first 24-72 h, indicating cardiomyocyte enrichment (Fig. 3 A, middle). After $6 \mathrm{~d}$ of puromycin treatment, most of the EBs consisted of strongly beating $\mathrm{EGFP}^{+}$clusters of cardiac cells (Fig. 3 A, right). Similar results were obtained with both hanging drops and mass culture in vitro differentiation protocols. Because the mass culture protocol typically yielded an order of magnitude more cardiomyocytes, it was used in all subsequent experiments.

As the cardiac cell mass appeared to increase during later puromycin selection (see Fig. $3 \mathrm{~A}$ and Video 1, available at http://www.jem.org/cgi/content/full/jem.20061469/DC1), we determined whether proliferation of ES cell-derived cardiomyocytes underlies this phenomenon. We found that the number of $\mathrm{EGFP}^{+}$cells increased dramatically during the first $3 \mathrm{~d}$ of puromycin selection and thereafter reached a plateau level

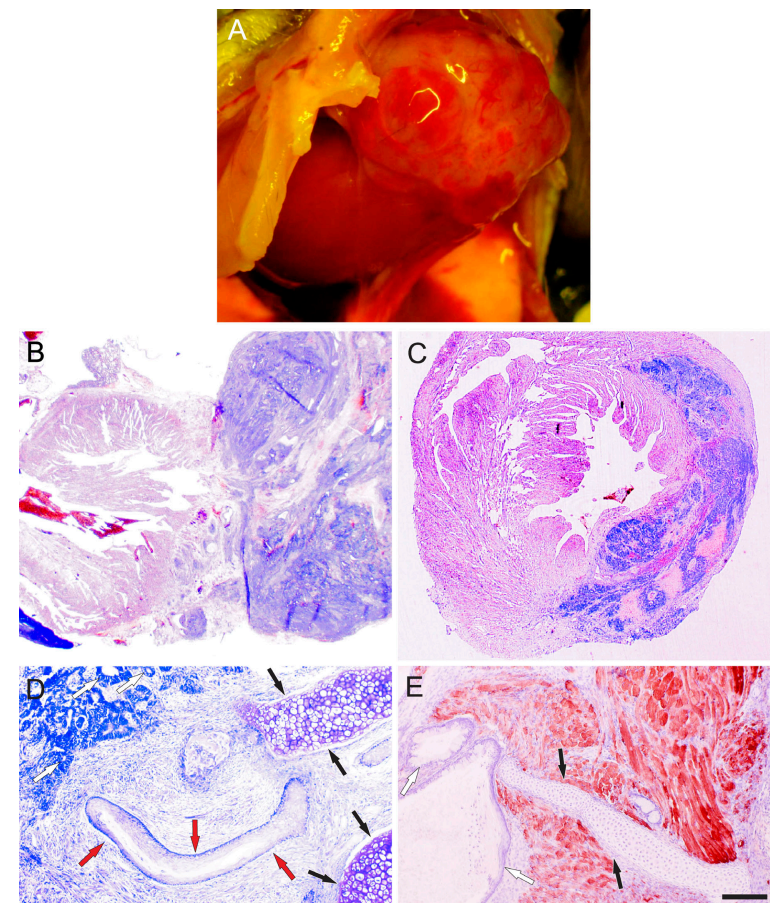

Figure 2. Teratoma formation after injection of undifferentiated ES cells and cut-out beating areas into the infarcted heart.

(A) Opened mouse chest in situ. In the apical part of the heart, a large tumor mass was seen $68 \mathrm{~d}$ after injecting $10^{5}$ cells obtained from EGFP+ beating areas of EBs. (B) Periodic acid Schiff-stained cross sections of this tumor showed exophytic tumor growth. (C) Mouse heart $31 \mathrm{~d}$ after injecting $10^{5}$ undifferentiated ES cells. Hematoxylin and eosin staining of cross sections in this heart revealed intracardiac tumor distribution. (D) Periodic acid Schiff staining evidenced cartilagineous (closed arrows), squamous (red arrows), and glandular (open arrows) differentiation. (E) Combined desmin (red) and toluidine blue staining proved differentiated cartilage (closed arrows), mucous glandular (open arrows), and red-stained muscle tissue. Bars: (B and C) $250 \mu \mathrm{m}$; (D and E) $150 \mu \mathrm{m}$.

yielding 6-10 times higher numbers of cardiomyocytes than in the untreated counterparts ( $n=4$; Fig. $3 \mathrm{~B}$ ). We confirmed this observation by labeling cardiomyocytes in the $\mathrm{S}$ phase using BrdU for $24 \mathrm{~h}$. We found that $32 \%$ of cardiomyocytes were $\mathrm{BrdU}^{+}$by day 3 of puromycin treatment compared with only $2 \%$ before the initiation of selection (Fig. 3, C and D). Thereafter, their number decreased to $\sim 13 \%$. In the untreated control cultures, no BrdU-labeled cardiomyocytes were detected at these stages of development $(n=2$; Fig. 3 D). To estimate the size of the proliferative pool of cardiomyocytes, the BrdU labeling time was increased from 24 to $72 \mathrm{~h}$ beginning on the third day of puromycin treatment $(n=2)$. This protocol revealed that $37 \%$ of $\alpha$ PIG $44-$ and $61 \%$ of $\alpha$ PIG10-derived cardiomyocytes had entered the cell cycle during the labeling period. From these results, the cell cycle length was calculated to be $18 \pm 4 \mathrm{~h}$ and that $\sim 50 \%$ of the cardiomyocytes cycled four to five times during the first $3 \mathrm{~d}$ of drug selection. This is in complete agreement with numbers obtained by cell counting (see Fig. 3 B), which indicated a $6-10-$ fold increase in the total number of cardiomyocytes induced by purification. 

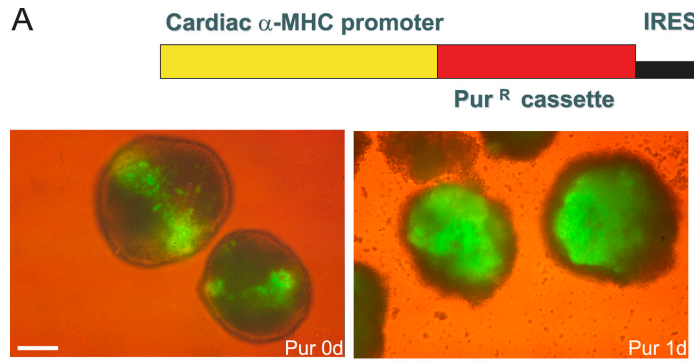

IRES
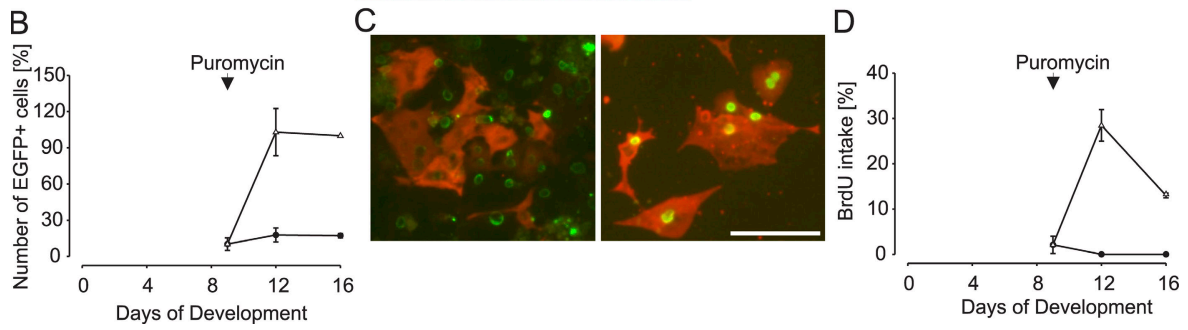

Figure 3. Puromycin-based selection and enrichment of ES cell-derived cardiomyocytes. (A) Scheme of the bicistronic vector (top). EGFP+ ${ }^{+}$areas in EBs at day 9 (left) and fast selection after addition of $10 \mu \mathrm{g} / \mathrm{ml}$ puromycin (middle and right). (B) Puromycin treatment induced a 6-10-fold increase in $\mathrm{EGFP}^{+}$cells (triangles) compared with untreated EBs (circles). Data were obtained from four experiments, and the cell number at day 16 was set for each experiment to

\section{Purity of puromycin-treated ES cell cultures}

For transplantation purposes, and to avoid tumor development, a very high purity of predifferentiated cardiomyocytes is absolutely required; therefore, we used a variety of different technical approaches to quantitatively assess the purity of puromycin-treated cultures and the extent of contamination with undifferentiated ES cells.

RT-PCR analysis using Oct-4 as a "bona fide" marker of undifferentiated mouse ES cells (19) showed that after $10 \mathrm{~d}$ of puromycin treatment no Oct-4 transcripts were detected by PCR (Fig. 4 A). This was further corroborated with Trypan blue staining by which untreated EBs contained $75 \%$ viable (Trypan blue $\left.{ }^{-}\right)$noncardiac $\left(\mathrm{EGFP}^{-}\right)$cells $(n=$ $1462)$, whereas this fraction decreased to $0.7 \%(n=884)$ after $10 \mathrm{~d}$ of puromycin selection (not depicted). Finally, to definitively assess the purity of drug-selected EBs, we counted the number of $\mathrm{EGFP}^{+}$and $\alpha$-actinin ${ }^{+}$cardiomyocytes versus noncardiomyocytes (Fig. 4 B). Consistent with previous results (9), only $1.8 \%$ of cells in the untreated EBs were cardiomyocytes $\left(\mathrm{EGFP}^{+}\right.$and $\alpha$-actinin ${ }^{+} ; n=1334$; Fig. 4 C, left). After puromycin treatment for 10 d, $99.4 \%$ of the cells were cardiomyocytes, whereas only $0.6 \%$ of all nucleated cells were noncardiomyocytes $(n=168$; Fig. 4 C, right). The identity of these puromycin-resistant noncardiomyocytes was not determined.

We have also established a simple and sensitive assay to determine the minimal time of puromycin required to eliminate all undifferentiated ES cells. The selected cardiomyocytes were seeded on feeder cells, and the growth of ES cell colonies was monitored in the absence of puromycin. When
100\% for the puromycin group. (C) BrdU labeling (green) and antiEGFP staining (Cy3, red) in untreated (left) and puromycin-treated ( $3 \mathrm{~d}$ after selection; right) EBs. (D) Statistics of BrdU labeling in untreated (circles) and treated (triangles) EBs. The number of proliferating cells was calculated after $24 \mathrm{~h}$ of BrdU incubation at days 0 , 3, or 7 of puromycin selection. Data were obtained from two independent experiments. Bars: (A) $250 \mu \mathrm{m}$; (C) $50 \mu \mathrm{m}$.

cardiac clusters were treated with puromycin for at least 9-10 d, no colony growth was observed and, therefore, this purification protocol was used for transplantation experiments.

The potential damage of cardiomyocytes by our novel lineage selection protocol was excluded with immunohistochemistry where structural integrity and the typical crossstriation were found (Fig. 4 B). Furthermore, puromycin-selected cardiomyocytes displayed normal action potentials at early and late stages of development (Fig. 5 A). As reported earlier for ES cell-derived and mouse embryonic cardiomyocytes (9), a significant shortening of the action potential duration at $90 \%$ repolarization (from $65.0 \pm 8.1 \mathrm{~ms}$ in briefly puromycin exposed [ $n=9$ ] to $25.3 \pm 4.9 \mathrm{~ms}$ in long puromycin exposed $[n=7])$ and a significantly more negative maximal diastolic potential $(-49.5 \pm 2.1 \mathrm{mV}$ in briefly exposed to $-58.1 \pm$ $1.7 \mathrm{mV}$ after long puromycin exposure) were clear indications that these cells were physiologically intact cardiomyocytes and differentiated during cultivation (Fig. 5 B). Our data demonstrate that puromycin selection induces formation of high purity $(>99 \%)$ of morphologically and physiologically intact cardiomyocytes.

\section{Transplantation of puromycin-selected ES cell-derived cardiomyocytes into injured hearts of syngeneic mice}

We next investigated the potential of purified ES cell-derived cardiomyocytes for engraftment and repair of the injured myocardium. ES cell-derived cardiomyocytes $\left(3 \times 10^{4}-10^{5}\right)$ were transplanted 9-12 d after puromycin selection into infarcted hearts of syngeneic mice. Surprisingly, poor engraftment of the transplanted cells was observed, as only $22 \%$ of 


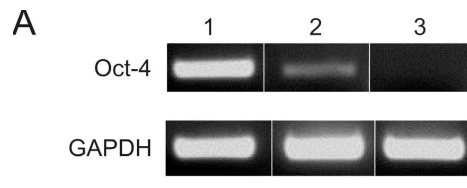

B

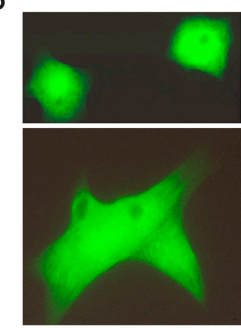

C

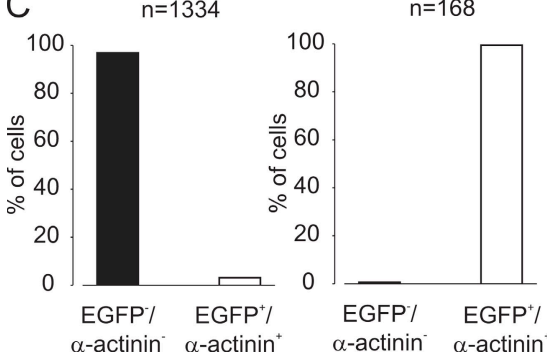

Figure 4. Purity of puromycin-selected ES cell-derived cardiomyocytes. (A) Oct-4 expression in undifferentiated ES cells (lane 1), beating EBs with EGFP+ areas plated for $9 \mathrm{~d}$ (lane 2), and EBs treated for $10 \mathrm{~d}$ with puromycin (lane 3). (B) $\alpha$-Actinin (Cy3, red) staining of puromycin-selected $\mathrm{EGFP}^{+}$cardiomyocytes (green); cell nuclei were stained with Hoechst dye (blue). (C) In 9-d-old EBs, $\sim 2 \%$ cardiomyocytes $\left(\mathrm{EGFP}^{+} / \alpha\right.$-actinin ${ }^{+} ; n=1334$, one representative experiment out of two; left graph) were found. After $10 \mathrm{~d}$ of puromycin selection, over $99 \%$ of cells were cardiomyocytes ( $n=168$; right graph). Bars: (B, top) $21 \mu \mathrm{m}$; (B, bottom) $12 \mu \mathrm{m}$.

mice $(n=9)$ contained any detectable $\mathrm{EGFP}^{+}$cells 3 wk after operation. We therefore reevaluated our earlier data in which embryonic heart-derived cells were found to stably engraft within the injured myocardium (17); analysis revealed that approximately half of the cells in embryonic hearts are cardiomyocytes, whereas the remaining noncardiomyocytes are primarily fibroblasts (20). We therefore determined whether fibroblasts might play a facilitating role for cardiomyocytes by co-cultivating purified ES cell-derived cardiomyocytes with fibroblasts. We found that purified cardiomyocytes did not adhere well to gelatin coated culture dishes and did not maintain their typical elongated shape of cardiomyocytes (Fig. 5 C, bottom). However, cardiomyocytes plated onto embryonic feeder cells maintained an elongated cell shape for weeks and even aligned with the fibroblasts (Fig. 5 C, top). Microelectrode array (MEA) recordings of field potentials in these cocultures revealed synchronous signals from electrodes in contact with $\mathrm{EGFP}^{+}$cardiomyocyte clusters over several weeks $(n=2$; Fig. 5 D). These results suggest that formation of a functional syncytium occurs between cardiomyocytes and fibroblasts.

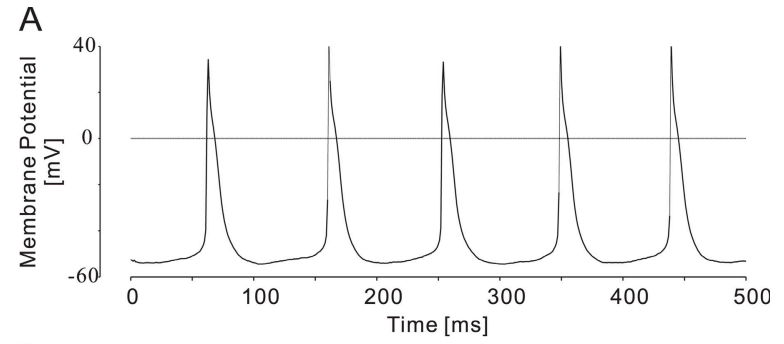

B
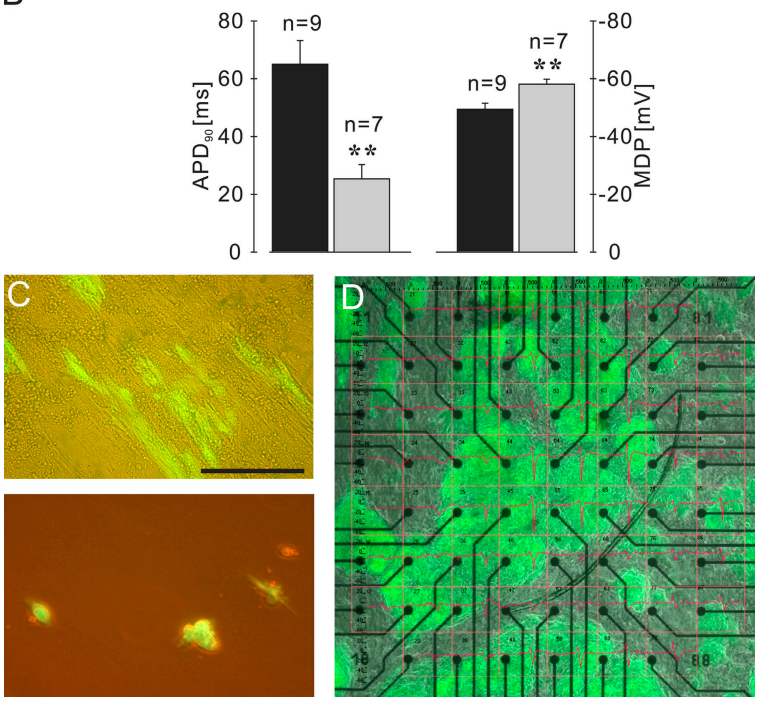

Figure 5. Characteristics of puromycin-selected ES cell-derived cardiomyocytes and interaction with fibroblasts. (A) Action potentials in an isolated $\mathrm{EGFP}^{+}$cardiomyocyte exposed for $16 \mathrm{~d}$ to puromycin. (B) Action potential duration at $90 \%$ repolarization $\left(\mathrm{APD}_{90}\right.$; left y axis; $\mathrm{P}<0.01$ ) and maximal diastolic potential (MDP; right y axis; $\mathrm{P}<0.01)$ at different time points of puromycin exposure (brief exposure [6-10 d], closed bars; long exposure [13-16 d], gray bars). (C) Morphology of $\mathrm{EGFP}^{+}$cardiomyocytes after co-cultivation with embryonic fibroblasts for $6 \mathrm{~d}$ (top) and on gelatin-coated dishes for $6 \mathrm{~d}$ (bottom). (D) Co-culture of $\mathrm{EGFP}^{+}$cardiomyocytes and embryonic fibroblasts on an MEA for recording field potentials (red traces). The image and the recordings were taken $4 \mathrm{~d}$ after starting the co-cultivation. Bars: (C) $100 \mu \mathrm{m}$; (D) $400 \mu \mathrm{m}$.

Based on these findings, we analyzed the effect of injecting equal numbers of puromycin-selected ES cell-derived cardiomyocytes and syngeneic fibroblasts into injured myocardium. This approach resulted in a substantial increase of cell engraftment. Prominent EGFP fluorescence, a reliable parameter for engraftment, was detected in $68.3 \%$ of operated hearts $(n=60)$ up to $147 \mathrm{~d}$ (mean $=63 \mathrm{~d})$ after cellular cardiomyoplasty (Fig. 6 A). Interestingly, the ratio of engraftment did not vary between middle $(<100 \mathrm{~d}, 68.2 \% ; n=44)$ and long-term $(>100 \mathrm{~d}, 68.7 \% ; n=16)$ transplantations, implying that graft rejection is not a prominent problem. Transplanted cardiomyocytes were localized within the border zones of damaged areas of the myocardium. In cryosections, an almost transmural distribution of the implanted cells could be observed (Fig. 6 B). The injected cells colocalized in clusters but could be clearly distinguished from the native cardiomyocytes because of their reduced size, distinct cell shape, and incomplete myofibrils 
shortly after transplantation, strongly supporting the conclusion that the $\mathrm{EGFP}^{+}$cells did not result from fusion with native cardiomyocytes. In the long-term transplants, the ES cell-derived cardiomyocytes displayed elongated cell shapes and distinct cross-striation, proving that the engrafted $\mathrm{EGFP}^{+}$ cells further differentiate after the transplantation (Fig. $6 \mathrm{C}$ ). We next examined the basis for intercellular coupling by analyzing gap junction formation based on connexin 43 staining. As depicted in Fig. 6 D, gap junctions were detected between the transplanted cardiomyocytes.

Although no tumors developed in 95\% $(n=60)$ of transplanted mouse hearts, three hearts harvested 45, 90, and $91 \mathrm{~d}$ after transplantation did reveal tumors, the latter two evolved from the same preparation of cells (Fig. 6 E). Histological analysis of two of these hearts revealed mesenchymal tumors closely resembling the pleomorphic variant of malignant fibrous histiocytoma and not teratomas (Fig. S1, available at http://www.jem.org/cgi/content/full/jem.20061469/DC1). Thus, our transplantation data indicate that undifferentiated
ES cells are completely eliminated by our lineage selection method, leading to an abolishment of teratoma formation after transplantation.

\section{Improvement of LVF after transplantation of puromycin- selected ES cell-derived cardiomyocytes and of contractility after in vitro transplantation}

To assess whether transplantation of ES cell-derived cardiomyocytes and fibroblasts resulted in enhancement of function in infarcted hearts, hemodynamics was determined 3-4 wk after surgery. Pressure-volume loops (Fig. 7 A) revealed a significant enhancement of LVEF $(\mathrm{P}<0.01 ; 51.6 \pm 6.2 \%$ vs. $36.3 \pm 11.1 \%)$ and reduction of the enddiastolic volume $(\mathrm{P}<0.05 ; 46.5 \pm 6.6 \mu \mathrm{l}$ vs. $58.5 \pm 18.4 \mu \mathrm{l})$ in mice with cardiomyoplasty $(n=12)$ versus sham injection $(n=11$; Fig. $7 \mathrm{~B}$ and Table S1). As a further control, we transplanted $10^{5} \mathrm{EGFP}^{+}$fibroblasts and analyzed LVF after 3-4 wk. In contrast to ES cell-derived cardiomyocytes, no difference in $\operatorname{LVEF}(53.6 \pm 7.1 \%$ vs. $50.3 \pm 6.1 \%$; Fig. $7 \mathrm{D}$ and Table S1)
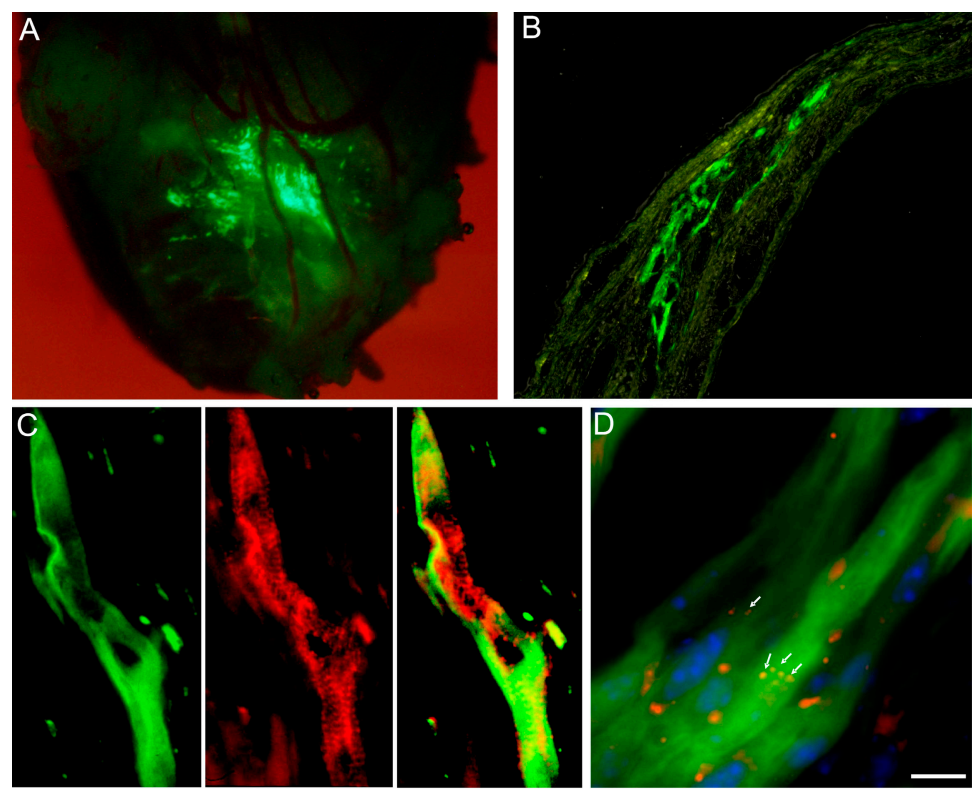

E

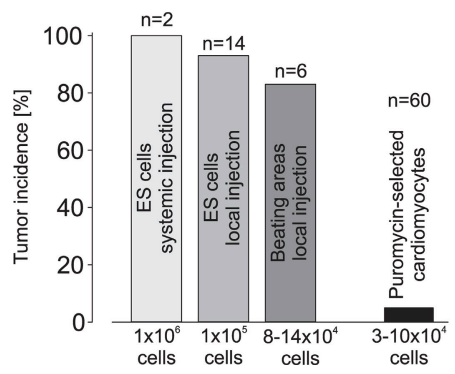

Figure 6. Engraftment of puromycin-selected ES cell-derived cardiomyocytes into injured hearts of syngeneic mice, including statistics of tumor incidence. (A) Engraftment of EGFP+ cardiomyocytes in an infarcted heart $40 \mathrm{~d}$ after injection of $10^{5} \mathrm{ES}$ cell-derived cardiomyocytes and $10^{5}$ embryonic fibroblasts. (B) Cross section of a heart $60 \mathrm{~d}$ after injecting $8 \times 10^{4} \mathrm{ES}$ cell-derived cardiomyocytes and $8 \times 10^{4}$ embryonic fibroblasts. (C) $\alpha$-Actinin staining (middle) of a transplanted, engrafted EGFP+ (left) ES cell-derived cardiomyocyte (overlay of the two images, right). (D) Immunostaining for connexin 43 (Cy3, red) showing gap junctions between the transplanted cardiomyocytes (arrows) and nuclear staining (blue) with Hoechst dye. (E) Statistics of tumor incidence. Bars: (B) $120 \mu \mathrm{m}$; (C) $17 \mu \mathrm{m}$; (D) $29 \mu \mathrm{m}$. 
and enddiastolic volume $(60.5 \pm 12.5 \mu \mathrm{l}$ vs. $57.0 \pm 12.2 \mu \mathrm{l})$ between the fibroblast $(n=6)$ and sham-injected $(n=6)$ mice was observed, although histological analysis proved good engraftment of the $\mathrm{EGFP}^{+}$fibroblasts (Fig. 7 C). We also tested the efficacy of transplanting $\mathrm{EGFP}^{+}$skeletal myoblasts $\left(10^{5}, n=5\right)$. These cells were found to engraft well into the lesion (Fig. S2, A and B, available at http://www.jem.org/cgi/content/full/jem.20061469/DC1), and LVEF was significantly enhanced $(\mathrm{P}<0.01 ; 60.6 \pm$ $2.8 \%[n=5]$ vs. $48.0 \pm 5.7 \%[n=5]$; Fig. S2 C and Table S1). Because skeletal myoblasts are proven to not integrate functionally into the myocardium, we presume that the improvement of heart function was mainly caused by the significant reduction of left enddiastolic volume $(\mathrm{P}<0.05$; $33.2 \pm 9.2 \mu \mathrm{l}$ vs. $51 \pm 8.7 \mu \mathrm{l})$.

Recent work (6) suggests that transplanted cells may act mainly via paracrine mechanisms. To determine whether the enhancement of LVF of ES cell-derived cardiomyocytes in vivo may be caused by active contribution rather than exclusively paracrine mechanisms, we assessed whether purified ES cell-derived cardiomyocytes generate force and transfer this to the surrounding tissue. For this purpose we established an "in vitro transplantation" model in which the purified ES cell-derived cardiomyocytes were transferred to ischemic ventricular slices (see scheme in Fig. $8 \mathrm{~A}$ ) and measured isometric force generation 1-2 wk after co-culture. Although ventricular slices without ES cells neither produced spontaneously nor after electrical stimulation any force $(n=4$; Fig. 8 B,D), ES cell-derived cardiomyocytes generated a force of
$6.1 \pm 0.8 \mu \mathrm{N}(n=5)$ at a spontaneous rate of $2.6 \pm 0.3 \mathrm{~Hz}$ and an even higher force of $8.6 \pm 1.7 \mu \mathrm{N}$ at a stimulation frequency of $3 \pm 0.4 \mathrm{~Hz}$ (Fig. $8, \mathrm{C}$ and D).

Hence, functional studies demonstrate that transplantation of puromycin-selected ES cell-derived cardiomyocytes results in engraftment, with clear augmentation of LVF in vivo and enhanced force of contraction in vitro.

\section{DISCUSSION}

The aim of this paper was to identify the most promising cell type for treatment of the infarcted heart. The investigation was largely motivated by the controversy surrounding the efficacy of adult BM cells and ES cells for cardiomyoplasty (for review see references 1,2). Although BM cells are easily accessible and allow autologous transplantations, it is still unclear and controversial whether these cells can improve defective heart function and whether this treatment is entirely safe. In fact, studies in animals suggest that cytokine treatment may carry the risk of accelerated restenosis of coronary arteries (21), and direct injection of BM cells may carry the risk of extended calcifications (22).

ES cells represent an ideal stem cell source for ex vivo generation of cardiomyocytes; however, studies are still missing in which their long-term, teratoma/tumor-free engraftment and enhancement of LVF are carefully evaluated. To address this critical topic, we used a highly reproducible infarction model and assessed the fate and functional relevance of transplanting ES cell-derived cardiomyocytes and compared this with the effect of transplanted BM cells, as
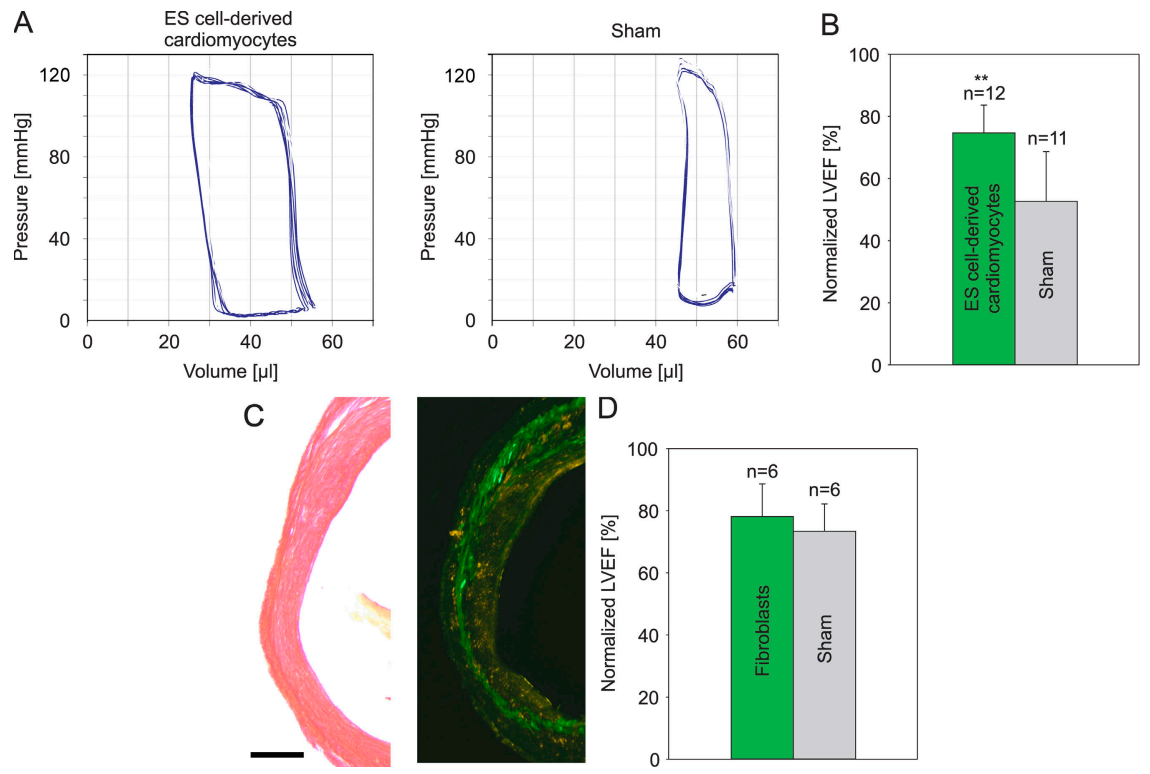

Figure 7. LVEF measurements after transplantation of ES cell-derived cardiomyocytes/fibroblasts or only fibroblasts. (A) Representative pressure-volume loops 3-4 wk after injecting $10^{5}$ ES cellderived cardiomyocytes and fibroblasts (left) or vehicle (right) into infarcted hearts. (B) Statistics of LVEF $(P<0.01)$. (C) Sirius red staining of injured myocardium (left) and engraftment of EGFP+ fibroblasts into the infarcted heart (right) after injection of $10^{5}$ embryonic fibroblasts. (D) Statistics of LVEF after injecting fibroblasts or vehicle $(P=0.42)$. LVEF in B (SV129) and D (C57BL/6) are normalized to data from respective congeneic WT mice. Original data are listed in Table S1. Note the difference in LVEF between the two mouse strains. Bars: (C, left) $250 \mu \mathrm{m}$; (C, right) $270 \mu \mathrm{m}$. 
well as fibroblasts and noncardiomyocytes. To avoid immunological interference and to be able to determine the tumorigenic risk of highly purified ES cell-derived cardiomyocytes, a syngeneic transplantation model was chosen. Thus, in case our purification approach of ES cell-derived cardiomyocytes turned out to be safe, it would be even safer in the clinically more relevant allogeneic setting (14). Nevertheless, the recent identification of pluripotent cells in testicles of adult mice revealed a therapeutically relevant new autologous ES cell-like source (23). Moreover, ongoing experiments on nuclear cloning and nuclear cloning-derived ES cells will soon also bring this approach closer to clinical application (24).

Our experimental results demonstrate that neither direct injection nor cytokine-induced mobilization of BM cells reduced scar formation and/or enhanced LVF 3-4 wk after injury. This time point was chosen to allow the engraftment and further differentiation of BM progenitors. Consistent with our earlier findings (5), we could not detect transdifferentiation of BM cells into cardiomyocytes using immunohistochemistry. To date the fate of transplanted BM cells has only been investigated with this approach, and we therefore have also performed single cell analysis using the patch-clamp technique whereby even the functional differentiation of BM cells into early embryonic cardiomyocytes (>E8.5) was excluded. We also could not detect, in contrast to earlier studies in mice (3) and human transplanted hearts (25), the contribution of BM cells to endothelial or smooth muscle cells of vessels in infarcted hearts. Our findings are corroborated by measurements of hemodynamics, where neither direct injection nor mobilization of BM cells had a positive impact in

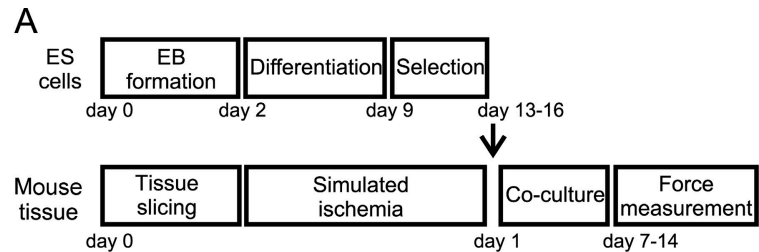

B
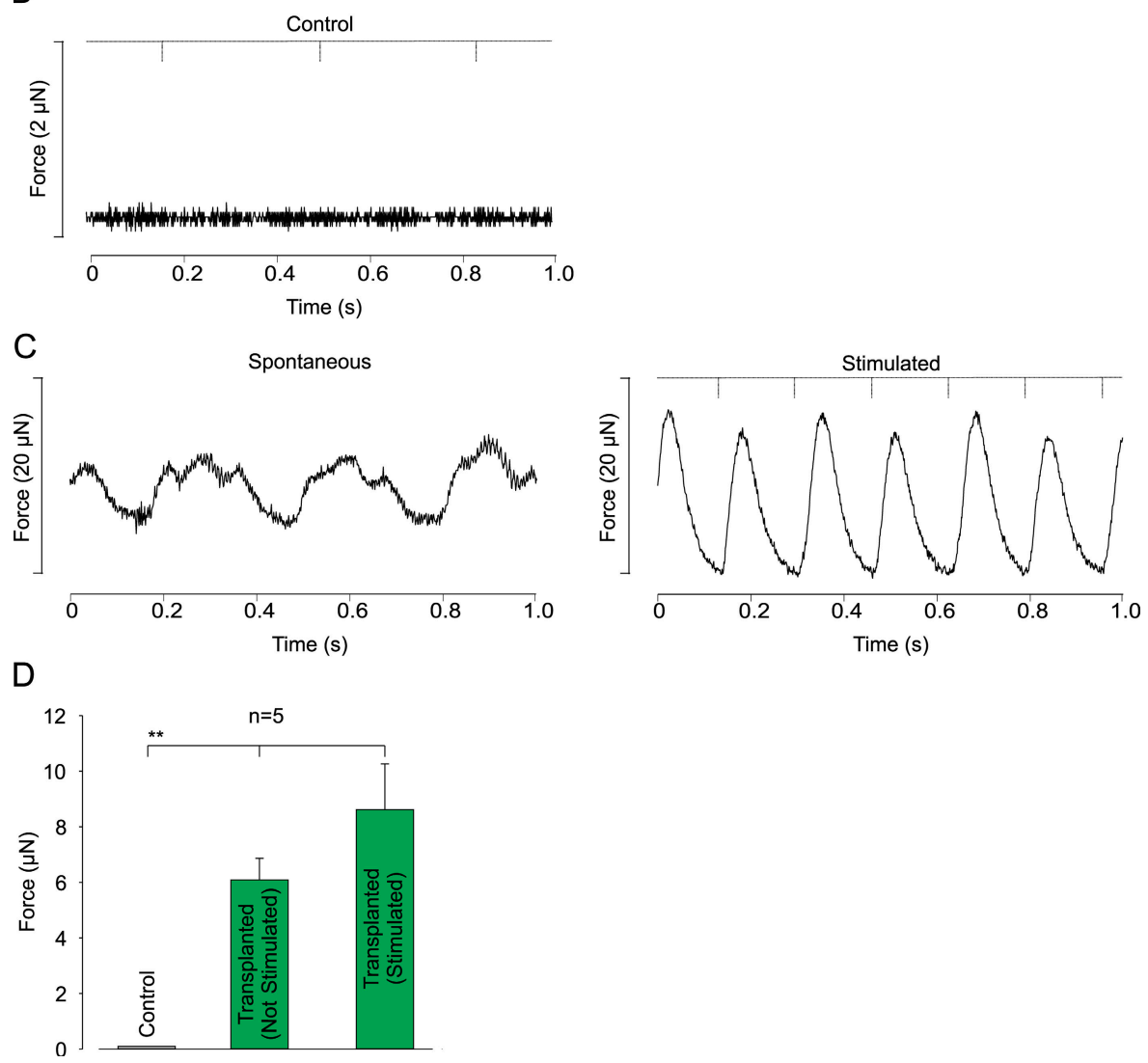

Figure 8. In vitro transplantation experiments. (A) Protocol of in vitro transplantation experiments. (B) Measurements of force generation in a stimulated (downward deflections on top bar) control slice without transplanted cells (note the different scaling). (C) Slices with ES cell-derived

cardiomyocytes generate force spontaneously (left) and after electrical stimulation (6 Hz, right). (D) Statistics of spontaneous and stimulated force generation in slices without (control) and with ES cell-derived cardiomyocytes $(P<0.001)$. 
contrast to earlier reports $(3,26)$. Thus, in a large number of animals, our studies exclude prominent neogenesis of cardiomyocytes and vessels from BM cells transplanted into infarcted hearts. Importantly, our results concur with recent clinical trials in which neither application of BM cells into affected coronary arteries (27) nor BM mobilization (28) had beneficial effects on LVF.

In clear contrast to the BM cells, highly purified ES cell-derived cardiomyocytes were found to long-term engraft (4-5 mo) and to clearly improve LVF. Because paracrine effects have been claimed to be potentially responsible for the beneficial effects observed after cellular cardiomyoplasty (6), we addressed this using an in vitro transplantation model. The experiments clearly proved that the ES cellderived cardiomyocytes generate force and transfer this to the surrounding tissue. Thus, if massive engraftment of ES cellderived cardiomyocytes into the infarcted myocardium is achieved, a strong functional improvement can be obtained.

In accordance with earlier work (29), we found that skeletal myoblasts engraft well into the infarcted myocardium and augment LVF. Because these cells are known to not couple electrically with the native myocardium (30) because of a lack of connexin 43 expression (31), their beneficial effect is most likely caused by stabilization of the scar region, resulting in a considerable reduction of the enddiastolic volume. However, their therapeutic use does not appear promising, as experimental data in vitro (32) and in vivo (33) indicate that skeletal myoblasts can induce ventricular arrhythmias via reentry; similar events have been also observed in the clinical trials (29).

The major challenge for clinical development of ES cellderived cardiomyocytes has been to develop safe and efficient methods for their enrichment in vitro, measures to ensure their long-term engraftment, and, most importantly, avoidance of tumorigenicity caused by contaminating ES cells. This prompted us to develop a cardiac lineage-specific selection to purify ES cell-derived cardiomyocytes. Unexpectedly, we discovered that elimination of noncardiomyocytes was accompanied by a burst of proliferation, which produced 6-10 times more cardiomyocytes. At this time we can only speculate about the underlying mechanisms and assume that noncardiomyocytes and/or undifferentiated ES cells normally produce factors that inhibit the proliferation of differentiating cardiomyocytes within the EBs.

Tumors are currently considered the major hurdle for ES cell-derived transplantation, as very few undifferentiated ES cells suffice for teratoma growth in the heart (this study), the brain (14), and the kidney (15). We have succeeded in establishing a highly purified ES cell-derived cardiomyocyte preparation $(>99 \%)$ and show, to our knowledge for the first time, in a large number of animals that teratoma formation after ES cell-based transplantation can be completely avoided, even long-term (4-5 mo), in syngeneic recipients. In fact, only 3 out of 60 hearts developed tumors, of which 2 were not teratomas but rather poorly differentiated mesenchymal tumors, and these most likely arose from the co-transplanted embryonic fibroblasts (the malignant fibrous histiocytoma looks predominantly fibroblast-like) (34). Our data also demonstrate that studies with much larger cohorts and longer follow-up periods than reported earlier $(10,13)$ are needed to assess the risk of tumor formation after transplantation of ES cell-derived cells.

Cellular replacement approaches in different tissues have proven to be of limited efficacy, as the transplanted cells are subject to a high rate of death within hours after transplantation (35). To date, the mechanisms responsible for this have been unclear but do not appear to be exclusively immune mediated, as similar rates of cell death are observed in the presence of immunosuppressants (20). Our experimental data imply that the extracellular matrix plays an important permissive role in cell survival and viability (36). This likely reflects the fact that fibroblasts provide extracellular matrix support for developing cardiomyocytes but also possibly critical growth factors and cytokines, as recently reported for the in vitro differentiation of cardiac progenitor cells into cardiomyocytes (37).

In conclusion, we show that ES cell-derived cardiomyocytes can be highly purified, enriched, and do long-term engraft in the infarcted heart without teratoma formation. Most importantly, our comparative study demonstrates that ES cell-derived cardiomyocytes are the most suitable candidates for cellular cardiomyoplasty, as these cells enhance, in contrast to BM cells, the contractile function of the lesioned myocardium.

\section{MATERIALS AND METHODS}

All animal experiments were approved by the local animal care committees of the Universities of Bonn, Cologne, and Lund.

Harvesting of $\mathrm{BM}$ cells and mobilization in reconstituted mice. BM cells were obtained by flushing femur and tibia with PBS using a 27-gauge needle. Mobilization of hematopoietic stem cells was performed as described previously (5). In brief, lethally irradiated mice were transplanted with congeneic $10^{6} \mathrm{EGFP}^{+}$(under control of the chicken $\beta$-actin promoter) whole BM cells, and multilineage hematopoietic reconstitution was evaluated at week 5 in peripheral blood. For mobilization, five daily injections of $5 \mu \mathrm{g}$ of recombinant human Flt-3 ligand and $5 \mu \mathrm{g}$ of recombinant mouse granulocyte/macrophage colony-stimulating factor were applied, starting $1 \mathrm{~h}$ after myocardial infarction.

Generation of transgenic ES cell clones. The pIRES2-EGFP vector (CLONTECH Laboratories, Inc.) was truncated via excision of the CMVIE promoter by AseI-NheI and religated. The $\alpha-\mathrm{MHC}$ promoter (5.5-kb BamHI-Sal I fragment) of the $\alpha-\mathrm{MHC}-\mathrm{pBK}$ plasmid (provided by J. Robbins, University of Cincinnati, Cincinnati, $\mathrm{OH}$ ) and the Puromycin ${ }^{\mathrm{R}}(\mathrm{Pac})$ cassette (HindIII-ClaI fragment) of the pCre-Pac vector were inserted into the multiple cloning site of the truncated pIRES2-EGFP vector. The $\alpha-\mathrm{MHC}-$ Pac-IRES-EGFP vector was linearized by SacI restrictase, and $40 \mu \mathrm{g}$ was used for transfection. Electroporation, G418 (Neomycin) selection, and propagation of clones was performed as reported previously (18).

ES cell differentiation and selection of cardiomyocytes. For ES cell differentiation, IMDM high glucose medium was supplemented with 20\% FCS (Invitrogen) in the absence of leukemia inhibitory factor. The hanging drop (18) and the mass culture protocol (see the following sentence) were used for cardiomyocyte differentiation from ES cells. For the mass culture protocol, ES cells were suspended in $3 \mathrm{ml}$ of differentiation medium (day 0) 
and placed on a horizontal shaker for $2 \mathrm{~d}$ to allow formation of EBs. These were diluted to a density of 100-200 EBs/10 $\mathrm{ml}$ and kept in differentiation medium. $\mathrm{EGFP}^{+}$areas in EBs were initially detected after 7-9 d of culture. $10 \mu \mathrm{g} / \mathrm{ml}$ puromycin was added on days 9-10, and the medium was subsequently changed every $2-3 \mathrm{~d}$. After $7-10 \mathrm{~d}$ of puromycin selection, EBs were isolated as previously reported (18).

Preparation of skeletal myoblasts and fibroblasts. $\mathrm{EGFP}^{+}$fibroblasts were prepared from transgenic C57BL/6 (under control of the chicken $\beta$-actin promoter) embryos (E14.5-15.5) using standard protocols. EGFP ${ }^{+}$ skeletal myoblasts were obtained from hindlimb muscles of transgenic C57BL/6 (under control of the cardiac- $\alpha$-actin promoter [38]) embryos (E18.5) using standard protocols.

Proliferation and viability assays. Cardiomyocyte numbers were determined at different time points in puromycin-treated and untreated EBs by digesting $100 \mathrm{EBs}$ and counting $\mathrm{EGFP}^{+}$cells. For BrdU labeling, the BrdU kit (Roche) was used in accordance with the manufacturer's protocol. In brief, EBs were incubated with BrdU for $24 \mathrm{~h}$ on days 0 or 3 or 7 of puromycin treatment, dissociated, and, after 2 more days, fixed and stained with anti-BrdU antibody. Because EGFP fluorescence is quenched by ethanol fixation, cells were immunostained using anti-GFP-rabbit polyclonal IgG (Santa Cruz Biotechnology, Inc.) and a Cy3-conjugated secondary antibody. Saturating BrdU labeling of EBs was achieved using incubation periods of $72 \mathrm{~h}$. The labeling index was calculated as the ratio of the $\mathrm{BrdU}^{+} / \mathrm{EGFP}^{+} / \mathrm{Cy}^{+}$of total $\mathrm{EGFP}^{+} / \mathrm{Cy}^{+}$cells. To assess cardiomyocyte proliferation, estimates of the proliferative pool and cell numbers during the first $3 \mathrm{~d}$ of puromycin treatment were introduced in the following formula: $\mathrm{T}_{\mathrm{C}}=\mathrm{Tx} \ln 2 / \ln N-\ln \mathrm{N}_{0}$ (where $\mathrm{T}_{\mathrm{C}}$ is the cell cycle length, $\mathrm{T}$ is the time after beginning of puromycin treatment [72 h], $\mathrm{N}_{0}$ is the cell number at the beginning of puromycin treatment, and $\mathrm{N}$ is the cell number after $72 \mathrm{~h}$ of puromycin treatment). Trypan blue ( $0.2 \%$; Invitrogen) exclusion was used to assess the viability of developing cells isolated from EBs. To reveal the number of cardiomyocytes after dissociation of EBs, $\alpha$-actinin (Sigma-Aldrich) immunostaining was performed in combination with Hoechst 33342 (Sigma-Aldrich).

RNA extraction and RT-PCR. Total RNA was prepared from $3 \times 10^{6}$ undifferentiated ES cells and 100-200 control or puromycin-treated (10 d) EBs. RNA was prepared as previously described (39). After the standard protocol (QIAGEN), $2 \mu \mathrm{l}$ of first-strand cDNA was used in a $20-\mu \mathrm{l}$ PCR reaction to detect the expression of Oct-4 (forward primer, 5'-AGGAAGCCGACAACAATGAG-3'; reverse primer, 5'-GAGCAGTGACGGGAACAGAG-3') and GAPDH (forward primer, 5'-TGTCAGCAATGCATCCTGCA-3'; reverse primer, $5^{\prime}$-CCGTTCAGCTCTGGGATGAC-3'). Samples without addition of reverse transcriptase served as negative controls. The PCR products were separated on $2 \%$ agarose by electrophoresis and documented by ethidium bromide staining on an UV transilluminator.

Myocardial infarction, transplantation of cells, and left ventricular catheterization. 12-wk-old male mice (strain SV 129 Ico/Pas for ES cells and C57BL/6 for all other cell types) were anesthetized, and a large cryolesion (4-mm diameter) or LCA ligation were generated as previously described (17). $3 \times 10^{6}$ EGFP transgenic ( $\beta$-actin promoter) unfractioned $\mathrm{BM}$ cells; $3 \times 10^{4}-10^{5}$ ES cell-derived cardiomyocytes and equal numbers of syngeneic embryonic fibroblasts; $10^{5}$ EGFP transgenic (human $\alpha$-actin promoter) embryonic (E18.5) skeletal myoblasts; or $10^{5}$ EGFP transgenic ( $\beta$-actin promoter) fibroblasts suspended in $5 \mu$ l of medium were injected into the center and border zones of the lesion. Control animals were injected with vehicle only.

3-4 wk after transplantation, LVEF was assessed on anesthetized mice using the Millar ARIA 1 system (Millar); the investigators were blinded. The LVEF was normalized with the data obtained from SV $129 \mathrm{Ico} / \mathrm{Pas}(n=7)$ or C57BL/6 $(n=6)$ control mice of the same age and sex, and these data are shown in the Fig. 1, O and P; Fig. 7, B and D; and Fig. S2. The original data of LVF are listed in Table S1.
Electrophysiology and extracellular recordings. Hearts of cryoinjured and mobilized mice were dissociated using a Langendorff system $(n=4)$ (20), and patch clamp recordings were performed in the whole cell configuration at room temperature. Voltage ramps ( -80 to $+50 \mathrm{mV}, 250 \mathrm{~ms}$ ) were used to identify inward and outward currents, and slow depolarizing current ramps (from a current corresponding to $-80 \mathrm{mV}, 10 \mathrm{~s}$ ) were used to evoke action potentials.

For experiments on ES cell-derived cardiomyocytes, the EBs were enzymatically dissociated, and electrophysiological recordings were performed 36-48 h later (9). Cardiomyocytes isolated after 6-10 d of puromycin treatment were considered to be briefly exposed, whereas a long exposure lasted 13-16 d.

For extracellular recordings, cardiomyocytes $\left(2 \times 10^{5}\right.$ cells $)$ and mitotically inactivated embryonic fibroblasts were seeded in the culture area of an MEA (Multi Channel Systems) (40). Spontaneous electrical activity was recorded with software (MC Rack; Multi Channel Systems) (41). Data were recorded simultaneously from 59 channels with a sampling frequency of $4 \mathrm{kHz}$.

In vitro transplantation using ES cell-derived cardiomyocytes. Ventricular slices were generated, as described previously (42), from neonatal mice (3-4 d after birth) of the strain SV129. The scheme of the co-culture of ventricular slices and puromycin-selected ES cell-derived cardiomyocytes is shown in Fig. $8 \mathrm{~A}$. In brief, slices were transferred into a hypoxia chamber and exposed to a nominally $\mathrm{O}_{2}$-free condition and a Tyrode's solution where glucose was replaced by equimolar concentrations of 2-deoxy-glucose for $4.5 \mathrm{~h}$. The slices were transferred to IMDM supplemented with $20 \%$ FCS and stored in the incubator $\left(37^{\circ} \mathrm{C}, 5 \% \mathrm{CO}_{2}\right)$ until co-culturing. Clusters of beating areas (24-30) of mouse ES cell-derived cardiomyocytes and slices were transferred into a custom-made well and co-cultured for 1-2 wk. The preparation was mounted on an isometric force transducer (Scientific Instruments) in IMDM without FCS, and the maximal force development $\left(\mathrm{L}_{\max }\right)$ was determined. The control ischemic slices without ES cell-derived cardiomyocytes did not produce force spontaneously and on stimulation (Fig. 8 B). Contractions were recorded from spontaneously beating and electrically stimulated preparations containing ES cell-derived cardiomyocytes; stimulation frequencies were only a little over $(\leq 27 \%)$ the spontaneous rate. Field stimulation was performed with silver electrodes $(0.5-10 \mathrm{~Hz}, 5-15 \mathrm{~V}$; stimulus pulse duration, $5 \mathrm{~ms}$ ) connected to a custom-made stimulator. Electrical stimuli and analogue signals from the force transducer (KG7A; range, $0-5 \mathrm{mN}$; resolution, $0.2 \mu \mathrm{N}$; resonance frequency, 250-300 Hz) were amplified with a bridge amplifier (BAM7C; Scientific Instruments), and analogue signals were transferred to an A/D board and recorded, as well as analyzed, using software (DasyLab version 7.0; National Instruments).

Histology and immunohistochemistry. Hearts were harvested, and engraftment of $\mathrm{EGFP}^{+}$cells was documented with a fluorescence microscope (SMZ 1000; Nikon). Histology/immunohistochemistry was performed as described previously (20). In brief, hearts were fixated in situ and cryopreserved for immunostainings. Serial sections were taken at 200-400 $\mu \mathrm{m}$ intervals to cover the whole infarcted area. Labeling was done using primary antibodies against $\alpha$-sarcomeric actinin (1:400; Sigma-Aldrich), ASMAC (1:400; Sigma-Aldrich), CD45 (1:400; Neomarkers), PECAM (1:400; BD Biosciences), von Willebrand factor (1:200; Chemicon International), and connexin 43 (1:400; Bio Trend). Primary antibodies were visualized by secondary antibodies conjugated to Cy3 and Cy5 (1:400; Dianova), and nuclei were stained with Hoechst 33342 (Sigma-Aldrich).

For analysis of cardiac differentiation, 27 sections of 6 hearts were investigated, and contribution to vessels was assessed in 69 sections of 10 hearts. Immunostainings were documented with an inverted microscope (Axiovert 200; Carl Zeiss MicroImaging, Inc.) equipped with a slider module (ApoTome; Carl Zeiss MicroImaging, Inc.).

Statistical analysis. Statistical significance was determined using the Student's $t$ test after confirmation of normal distribution. $\mathrm{P}<0.05$ was considered significant. All errors are SD, with the exception of the electrophysiological 
and contraction parameters in Fig. 1, L-N; Fig. 5 B; and Fig. 8 D, which are shown as SEM.

Online supplemental material. Table S1 measured and normalized (WT mice) values of LVEF. Video 1 shows long-term observation of a transgenic EB before and during puromycin selection. Fig. S1 depicts formation of malignant fibrous histiocytoma $90 \mathrm{~d}$ after transplantation of puromycinselected ES cell-derived cardiomyocytes. Fig. S2 shows engraftment and LEVF after transplantation of skeletal myoblasts. Online supplemental material is available at http://www.jem.org/cgi/content/full/jem.20061469/DC1.

We thank C. Böttinger, M. Czechowski, F. Holst, P. Metzger, and L. Rochlin for cell culture work; C. Sekhar for help with the vector construct; E. Ratering for cell preparation; Dr. Liu and A. Koester for help with histological analysis and immunohistochemistry; and Dr. B. Freedman for carefully reading the manuscript.

This study was supported by grants from the Deutsche

Forschungsgemeinschaft (273-2/3 to W. Roell and B.K. Fleischmann); the Köln Fortune Program (157/2003 to F. Pillekamp); the Swedish Research Council and the Swedish Heart and Lung Foundation (to S.E. Jacobsen and S. Jovinge); and the scientific exchange program North Rhine Westphalia-Sweden.

The authors have no conflicting financial interests.

Submitted: 11 July 2006

Accepted: 10 August 2006

\section{REFERENCES}

1. Laflamme, M.A., and C.E. Murry. 2005. Regenerating the heart. Nat. Biotechnol. 23:845-856.

2. Murry, C.E., L.J. Field, and P. Menasche. 2005. Cell-based cardiac repair: reflections at the 10-year point. Circulation. 112:3174-3183.

3. Orlic, D., J. Kajstura, S. Chimenti, I. Jakoniuk, S.M. Anderson, B. Li, J. Pickel, R. McKay, B. Nadal-Ginard, D.M. Bodine, et al. 2001. Bone marrow cells regenerate infarcted myocardium. Nature. 410:701-705.

4. Murry, C.E., M.H. Soonpaa, H. Reinecke, H. Nakajima, H.O. Nakajima, M. Rubart, K.B. Pasumarthi, J.I. Virag, S.H. Bartelmez, V. Poppa, et al. 2004. Haematopoietic stem cells do not transdifferentiate into cardiac myocytes in myocardial infarcts. Nature. 428:664-668.

5. Nygren, J.M., S. Jovinge, M. Breitbach, P. Sawen, W. Roll, J. Hescheler, J. Taneera, B.K. Fleischmann, and S.E. Jacobsen. 2004. Bone marrow-derived hematopoietic cells generate cardiomyocytes at a low frequency through cell fusion, but not transdifferentiation. Nat. Med. 10:494-501.

6. Gnecchi, M., H. He, O.D. Liang, L.G. Melo, F. Morello, H. Mu, N. Noiseux, L. Zhang, R.E. Pratt, J.S. Ingwall, and V.J. Dzau. 2005. Paracrine action accounts for marked protection of ischemic heart by Akt-modified mesenchymal stem cells. Nat. Med. 11:367-368.

7. Xiang, G., M.D. Schuster, T. Seki, A.A. Kocher, S. Eshghi, A. Boyle, and S. Itescu. 2004. Down-regulation of plasminogen activator inhibitor 1 expression promotes myocardial neovascularization by bone marrow progenitors. J. Exp. Med. 200:1657-1666.

8. Odorico, J.S., D.S. Kaufman, and J.A. Thomson. 2001. Multilineage differentiation from human embryonic stem cell lines. Stem Cells. 19:193-204.

9. Kolossov, E., Z. Lu, I. Drobinskaya, N. Gassanov, Y. Duan, H. Sauer, O. Manzke, W. Bloch, H. Bohlen, J. Hescheler, and B.K. Fleischmann. 2005. Identification and characterization of embryonic stem cellderived pacemaker and atrial cardiomyocytes. FASEB J. 19:577-579.

10. Klug, M.G., M.H. Soonpaa, G.Y. Koh, and L.J. Field. 1996. Genetically selected cardiomyocytes from differentiating embryonic stem cells form stable intracardiac grafts. J. Clin. Invest. 98:216-224.

11. Zandstra, P.W., C. Bauwens, T. Yin, Q. Liu, H. Schiller, R. Zweigerdt, K.B. Pasumarthi, and L.J. Field. 2003. Scalable production of embryonic stem cell-derived cardiomyocytes. Tissue Eng. 9:767-778.

12. Behfar, A., L.V. Zingman, D.M. Hodgson, J.M. Rauzier, G.C. Kane, A. Terzic, and M. Puceat. 2002. Stem cell differentiation requires a paracrine pathway in the heart. FASEB J. 16:1558-1566.

13. Menard, C., A.A. Hagege, O. Agbulut, M. Barro, M.C. Morichetti, C. Brasselet, A. Bel, E. Messas, A. Bissery, P. Bruneval, et al. 2005.
Transplantation of cardiac-committed mouse embryonic stem cells to infarcted sheep myocardium: a preclinical study. Lancet. 366:1005-1012.

14. Erdo, F., C. Buhrle, J. Blunk, M. Hoehn, Y. Xia, B. Fleischmann, M. Focking, E. Kustermann, E. Kolossov, J. Hescheler, et al. 2003. Host-dependent tumorigenesis of embryonic stem cell transplantation in experimental stroke. J. Cereb. Blood Flow Metab. 23:780-785.

15. Lawrenz, B., H. Schiller, E. Willbold, M. Ruediger, A. Muhs, and S. Esser. 2004. Highly sensitive biosafety model for stem-cell-derived grafts. Cytotherapy. 6:212-222.

16. Laflamme, M.A., J. Gold, C. Xu, M. Hassanipour, E. Rosler, S. Police, V. Muskheli, and C.E. Murry. 2005. Formation of human myocardium in the rat heart from human embryonic stem cells. Am. J. Pathol. 167:663-671.

17. Roell, W., Y. Fan, Y. Xia, E. Stoecker, P. Sasse, E. Kolossov, W. Bloch, H. Metzner, C. Schmitz, K. Addicks, et al. 2002. Cellular cardiomyoplasty in a transgenic mouse model. Transplantation. 73:462-465.

18. Kolossov, E., B.K. Fleischmann, Q. Liu, W. Bloch, S. ViatchenkoKarpinski, O. Manzke, G.J. Ji, H. Bohlen, K. Addicks, and J. Hescheler. 1998. Functional characteristics of ES cell-derived cardiac precursor cells identified by tissue-specific expression of the green fluorescent protein. J. Cell Biol. 143:2045-2056.

19. Nichols, J., B. Zevnik, K. Anastassiadis, H. Niwa, D. Klewe-Nebenius, I. Chambers, H. Scholer, and A. Smith. 1998. Formation of pluripotent stem cells in the mammalian embryo depends on the POU transcription factor Oct4. Cell. 95:379-391.

20. Roell, W., Z.J. Lu, W. Bloch, S. Siedner, K. Tiemann, Y. Xia, E. Stoecker, M. Fleischmann, H. Bohlen, R. Stehle, et al. 2002. Cellular cardiomyoplasty improves survival after myocardial injury. Circulation. 105:2435-2441

21. Kang, H.J., H.S. Kim, S.Y. Zhang, K.W. Park, H.J. Cho, B.K. Koo, Y.J. Kim, L.D. Soo, D.W. Sohn, K.S. Han, et al. 2004. Effects of intracoronary infusion of peripheral blood stem-cells mobilised with granulocyte-colony stimulating factor on left ventricular systolic function and restenosis after coronary stenting in myocardial infarction: the MAGIC cell randomised clinical trial. Lancet. 363:751-756.

22. Yoon, Y.S., J.S. Park, T. Tkebuchava, C. Luedeman, and D.W. Losordo. 2004. Unexpected severe calcification after transplantation of bone marrow cells in acute myocardial infarction. Circulation. 109:3154-3157.

23. Guan, K., K. Nayernia, L.S. Maier, S. Wagner, R. Dressel, J.H. Lee, J. Nolte, F. Wolf, M. Li, W. Engel, and G. Hasenfuss. 2006. Pluripotency of spermatogonial stem cells from adult mouse testis. Nature. 440:1199-1203.

24. Brambrink, T., K. Hochedlinger, G. Bell, and R. Jaenisch. 2006. ES cells derived from cloned and fertilized blastocysts are transcriptionally and functionally indistinguishable. Proc. Natl. Acad. Sci. USA. 103:933-938.

25. Minami, E., M.A. Laflamme, J.E. Saffitz, and C.E. Murry. 2005. Extracardiac progenitor cells repopulate most major cell types in the transplanted human heart. Circulation. 112:2951-2958.

26. Orlic, D., J. Kajstura, S. Chimenti, F. Limana, I. Jakoniuk, F. Quaini, B. Nadal-Ginard, D.M. Bodine, A. Leri, and P. Anversa. 2001. Mobilized bone marrow cells repair the infarcted heart, improving function and survival. Proc. Natl. Acad. Sci. USA. 98:10344-10349.

27. Janssens, S., C. Dubois, J. Bogaert, K. Theunissen, C. Deroose, W. Desmet, M. Kalantzi, L. Herbots, P. Sinnaeve, J. Dens, et al. 2006. Autologous bone marrow-derived stem-cell transfer in patients with ST-segment elevation myocardial infarction: double-blind, randomised controlled trial. Lancet. 367:113-121.

28. Zohlnhofer, D., I. Ott, J. Mehilli, K. Schomig, F. Michalk, T. Ibrahim, G. Meisetschlager, J. von Wedel, H. Bollwein, M. Seyfarth, et al. 2006. Stem cell mobilization by granulocyte colony-stimulating factor in patients with acute myocardial infarction: a randomized controlled trial. JAMA. 295:1003-1010

29. Menasche, P., A.A. Hagege, J.T. Vilquin, M. Desnos, E. Abergel, B. Pouzet, A. Bel, S. Sarateanu, M. Scorsin, K. Schwartz, et al. 2003 Autologous skeletal myoblast transplantation for severe postinfarction left ventricular dysfunction. J. Am. Coll. Cardiol. 41:1078-1083.

30. Leobon, B., I. Garcin, P. Menasche, J.T. Vilquin, E. Audinat, and S. Charpak. 2003. Myoblasts transplanted into rat infarcted myocardium 
are functionally isolated from their host. Proc. Natl. Acad. Sci. USA. 100:7808-7811.

31. Reinecke, H., V. Poppa, and C.E. Murry. 2002. Skeletal muscle stem cells do not transdifferentiate into cardiomyocytes after cardiac grafting. J. Mol. Cell. Cardiol. 34:241-249.

32. Abraham, M.R., C.A. Henrikson, L. Tung, M.G. Chang, M. Aon, T. Xue, R.A. Li, B. O'Rourke, and E. Marban. 2005. Antiarrhythmic engineering of skeletal myoblasts for cardiac transplantation. Circ. Res. 97:159-167.

33. Fernandes, S., J.C. Amirault, G. Lande, J.M. Nguyen, V. Forest, O. Bignolais, G. Lamirault, D. Heudes, J.L. Orsonneau, M.F. Heymann, et al. 2006. Autologous myoblast transplantation after myocardial infarction increases the inducibility of ventricular arrhythmias. Cardiovasc. Res. 69:348-358.

34. Vander Salm, T.J. 2000. Unusual primary tumors of the heart. Semin. Thorac. Cardiovasc. Surg. 12:89-100.

35. Yasuda, T., R.D. Weisel, C. Kiani, D.A. Mickle, M. Maganti, and R.K. Li. 2005. Quantitative analysis of survival of transplanted smooth muscle cells with real-time polymerase chain reaction. J. Thorac. Cardiovasc. Surg. 129:904-911.

36. Deschamps, A.M., and F.G. Spinale. 2005. Matrix modulation and heart failure: new concepts question old beliefs. Curr. Opin. Cardiol. 20:211-216.

37. Laugwitz, K.L., A. Moretti, J. Lam, P. Gruber, Y. Chen, S. Woodard, L.Z. Lin, C.L. Cai, M.M. Lu, M. Reth, et al. 2005. Postnatal isl1+ cardioblasts enter fully differentiated cardiomyocyte lineages. Nature. 433:647-653

38. Fleischmann, M., W. Bloch, E. Kolossov, C. Andressen, M. Muller, G. Brem, J. Hescheler, K. Addicks, and B.K. Fleischmann. 1998. Cardiac specific expression of the green fluorescent protein during early murine embryonic development. FEBS Lett. 440:370-376.

39. Fleischmann, B.K., Y. Duan, Y. Fan, T. Schoneberg, A. Ehlich, N. Lenka, S. Viatchenko-Karpinski, L. Pott, J. Hescheler, and B. Fakler. 2004. Differential subunit composition of the G protein-activated inward-rectifier potassium channel during cardiac development. J. Clin. Invest. 114:994-1001.

40. Igelmund, P., B.K. Fleischmann, I.R. Fischer, J. Soest, O. Gryshchenko, M.M. Bohm-Pinger, H. Sauer, Q. Liu, and J. Hescheler. 1999. Action potential propagation failures in long-term recordings from embryonic stem-cell derived cardiomyocytes in tissue culture. Pflugers Arch. 437:669-679.

41. Stett, A., U. Egert, E. Guenther, F. Hofmann, T. Meyer, W. Nisch, and H. Haemmerle. 2003. Biological application of microelectrode arrays in drug discovery and basic research. Anal. Bioanal. Chem. 377:486-495.

42. Pillekamp, F., M. Reppel, V. Dinkelacker, Y. Duan, N. Jazmati, W. Bloch, K. Brockmeier, J. Hescheler, B.K. Fleischmann, and R. Koehling. 2005. Establishment and characterization of a mouse embryonic heart slice preparation. Cell. Physiol. Biochem. 16:127-132. 